Aim of the study: Pulmonary pleomorphic carcinoma (PPC) of the lung is a subset of poorly differentiated non-small cell lung cancers (NSCLCS). Because of its rarity, information on epidermal growth factor receptor (EGFR) and Kirsten rat sarcoma viral oncogene (KRAS) mutations is controversial and sparse. The aim was to investigate the two key oncogenes' characteristics and their correlation with clinical variables.

Material and methods: We retrospectively screened 110 paraffin-embedded surgically resected specimens from patients with PPC. Of these, follow-up information was available for 48 patients. We then successfully analyzed 70 PPC samples and examined EGFR and KRAS mutation status by direct sequencing. The findings were correlated with a control group of patients with other NSCLCs.

Results: In our department, PPC comprised about $1.57 \%$ of surgical resected cases (110/6990). 37.4\% of patients smoked. EGFR mutations were detected in 11 cases (15.7\%), with a significantly higher frequency in women than men $(p=0.011)$. KRAS mutations were detected in 10 cases (14.3\%) and were more often found at age 65 or older $(p=0.02)$. Of interest, in PPC, all KRAS mutations occurred in never smokers. Also, most never smokers have transversion mutations $(G \rightarrow T)$ in PPCs and other NSCLCs. Conclusions: Our results demonstrated a similar EGFR and KRAS mutation rate in Chinese PPC patients. EGFR tyrosine kinase inhibitors may be a treatment option for PPCs with EGFR mutations. Of note, EGFR mutations in PPC were commonly identified in women; therefore women should be high-priority candidates for mutation screening.

Key words: pulmonary pleomorphic carcinoma, EGFR mutation, KRAS mutation.

Contemp Oncol (Pozn) 2015; 19 (1): 22-27 DOI: $10.5114 /$ wo.2014.43491

\section{EGFR and KRAS mutations in pulmonary pleomorphic carcinoma and their correlation with clinicopathologic features}

\author{
Xiaoli Jia, Gang Chen
}

Department of Pathology, Shanghai Pulmonary Hospital, Tongji University School of Medicine, Shanghai, China

\section{Introduction}

Pulmonary pleomorphic carcinoma (PPC) is an uncommon heterogeneous tumor of non-small cell lung carcinomas (NSCLCS). The reported incidence of PPC in the literature has ranged from $0.1 \%$ to $1.6 \%$ of all lung cancer [1-3]. According to the WHO classification of lung tumors, PPC is defined as a carcinoma consisting of spindle and giant cells alone or NSCLC combined with a sarcomatoid tumor component of at least 10\% [4-6]. Several studies have reported that many lung adenocarcinomas (ADs) are highly sensitive to tyrosine kinase inhibitors (TKIs), and most of these patients are from the Asian, female, nonsmoker population [7-10]. However, the information on the epidermal growth factor receptor (EGFR) and Kirsten rat sarcoma viral oncogene (KRAS) mutation status of PPC is sparse and controversial because of its rarity. And whether EGFR inhibitor therapy might be effective in patients with PPC is not yet clear. Italiano et al. reported the lack of EGFR mutation and high rate of KRAS mutation. Most patients with PPC were not likely to benefit from EGFR-targeted therapies [11, 12]. Nonetheless, a number of other studies show the existence of EGFR mutation, and a low KRAS mutation incidence rate [13-15]. Factors such as the small series of patients, and geographical or racial variation, might explain these differences. Moreover, the incidence of EGFR mutations in Chinese PPC patients has not been defined.

In the current study, therefore, we examine the EGFR and KRAS mutation status in a relatively large series of surgically treated PPC specimens, and investigate the association of several clinical variables with the EGFR and KRAS mutation, in order to identify useful information on patient selection for targeted therapy.

\section{Material and methods}

\section{Tumor cases}

Between February 2007 and February 2011, a total of 6990 patients with NSCLC were treated surgically in the Department of Thoracic Surgery, Shanghai Pulmonary Hospital, Shanghai, China. A total of 110 cases of PPC (1.57\%) and 225 other cases of NSCLC, i.e., 113 ADs, 40 squamous cell carcinomas (SQs), 55 adenosquamous carcinomas (ADSQs) and 17 large cell carcinomas (LCCS) of lung, were collected and diagnosed strictly using the WHO classification [4]. In every case, we used formalin-fixed and paraffin-embedded tissues from resections. All slides were reviewed blindly by 2 pathologists. In addition, in each case of PPC, the epithelial immunophenotype of the tumor was confirmed using markers of AD (TTF1, SPA and SPB) and SQ (p63, CK5/6 and 34 E12). We also performed additional immunohistochemical (IHC) stains for Vimtion to demonstrate sarcoma. Clinical information, including patient sex, age at diagnosis, and smoking history was obtained for all these cases. Testing 
for EGFR and KRAS mutations was successfully analyzed in 70 PPCs and 225 other cases. This study was approved by the institutional review boards, and appropriate written informed consent was obtained from all patients.

\section{DNA extraction and sequencing analysis}

For mutation detection, DNA was extracted from the formalin-fixed, paraffin-embedded tumor sections. EGFR exon 19 and 21 and KRAS codon 12 and 13 mutations were detected using direct-sequencing polymerase chain reaction as previously described [16]. To minimize necrosis and normal cell genomic DNA contamination, tumor areas were selected by manual microdissection of HE stained slides.

\section{Statistical analysis}

The data were analyzed using SPSS version 17.0 for Windows. Correlations between clinicopathologic and molecular factors were determined using the $\chi^{2}$ and Fisher exact tests. The Mann-Whitney $U$ test was used to detect significant differences in patient age and tumor size. Overall survival was defined as the time from surgical resection until the date of death or last follow-up for patients who remained alive. Survival curves were analyzed using the Kaplan-Meier method and compared by using the log-rank test. Univariate and multivariate relative risk were calculated using Cox proportional hazards regression. Two-sided $p$ values of less than 0.05 were considered to indicate statistical significance.

\section{Results}

Clinicopathologic characteristics of the 110 pulmonary pleomorphic carcinomas and comparison with other non-small cell lung carcinomas

Clinicopathological characteristics of all 110 PPC and other NSCLC patients are compiled in Table 1. Briefly, the case series included 92 men and 18 women ( $M$ : F ratio $5: 1$ ), aged from 38 to 78 years (median 62 years). There were 39 smokers, and 71 never smokers. The median diameter of the tumor was $4.5 \mathrm{~cm}(1-14 \mathrm{~cm})$. The locations of the lesions were as follows: in 24 cases they were in the central, in 84 cases in the peripheral, and in 2 cases in both locations.

With respect to the comparison of clinicopathologic features, higher age $(p=0.027)$, male sex $(p=0.001)$, smoker $(p=0.039)$, and larger tumor size $(p=0.000)$ were significantly more common in the group of 110 PPCs than in the other group of 225 NSCLCS (Table 1), but the difference of tumor site was not statistically significant $(p=0.251)$.

\section{Histologic features and mutational analysis of 70 pulmonary pleomorphic carcinomas}

Sequence analysis of EGFR and KRAS genes was performed on 70 PPCs. On the basis of microscopic examination and IHC staining results, we could identify 18 tumors consisting of spindle cells and giant cells alone, and 52 contained identifiable epithelial components (36 cases showed AD, 7 had SQ, 8 had ADSQ and 1 had LCC).

We identified 11 mutations (15.7\%) in EGFR and 10 mutations (14.3\%) in KRAS. In particular, EGFR mutations con- sisted of 2 frame deletions in exon 19 (E746 A750del), and 9 amino acid substitutions in exon 21 (L858 $\bar{R}$ ). All KRAS codon 12 and 13 mutations were missense mutations (G12C in 5 cases, G12D in 2, G12V in 1, G12A in 1, and G13C in 1), and all these patients were non-smokers. No mutations were observed simultaneously in both EGFR and KRAS genes (Table 2). Also, 10 PPCs with EGFR mutated had an identifiable epithelial component (6 ADs, 3 ADSQ and 1SQ) and 1 was classified as pure PPC consisting only of spindle and giant cells. KRAS mutation was found in 8 cases with an epithelial component (6 ADs, 1 ADSQ and 1 SQ), and 2 showed only mesenchymal elements (Table 3 ).

For most mutated patients, different areas corresponding to the epithelial and sarcomatoid components were intimately admixed. Only in two EGFR and one KRAS mutated cases (patients 1, 5 and 19) were the two elements clearly distinct from each other. Therefore, we were able to easily select by manual microdissection, and analyze independently, both the epithelial and the sarcomatoid elements. The same EGFR and KRAS mutations were detected in the two different histological components in all three cases.

\section{Comparison of EGFR and KRAS mutations with those of other non-small cell lung carcinomas}

In comparison with PPCs, there was a higher EGFR mutation rate $(42.5 \%)$ and lower KRAS mutation rate (4.42\%) in the AD group, and the difference was significant ( $p=$ $=0.000$ ). When the rates of EGFR mutation between PPC and SQ groups were compared alone, near significance was achieved ( $p=0.053)$. Moreover, ADSQ group had a higher mutation rate of EGFR ( $p=0.007)$ than PPC group, whereas the statistical significance between the two groups in KRAS mutation rate was borderline $(p=0.065)$ (Table 2). Further, we compared the different type of KRAS mutation in these patients. The most frequent type of

Table 1. Clinicopathologic characteristics of the 110 pulmonary pleomorphic carcinomas and the comparison with other NSCLCs

\begin{tabular}{|c|c|c|c|}
\hline Characteristic & $\begin{array}{c}\text { Pleomorphic } \\
\text { carcinoma } \\
n=110(\%)\end{array}$ & $\begin{array}{c}\text { Other } \\
\text { NSCLC } \\
n=225(\%)\end{array}$ & $p$ \\
\hline $\begin{array}{l}\text { Age }(y) \\
\text { median } \\
\text { range }\end{array}$ & $\begin{array}{c}62 \\
38-78\end{array}$ & $\begin{array}{c}59 \\
30-79\end{array}$ & 0.027 \\
\hline $\begin{array}{l}\text { Sex } \\
\text { male } \\
\text { female }\end{array}$ & $\begin{array}{l}92(83.5) \\
18(16.5)\end{array}$ & $\begin{array}{c}137(60.9) \\
88(39.1)\end{array}$ & 0.001 \\
\hline $\begin{array}{l}\text { Smoking history } \\
\text { smoker } \\
\text { never smoker }\end{array}$ & $\begin{array}{l}39(37.4) \\
71(62.6)\end{array}$ & $\begin{array}{c}55(24.4) \\
170(75.5)\end{array}$ & 0.039 \\
\hline $\begin{array}{l}\text { Tumor size }(\mathrm{cm}) \\
\text { median } \\
\text { range }\end{array}$ & $\begin{array}{c}4.5 \\
1-14\end{array}$ & $\begin{array}{c}3 \\
0.4-12\end{array}$ & 0.000 \\
\hline $\begin{array}{l}\text { Tumor site } \\
\text { central } \\
\text { predilection } \\
\text { central and } \\
\text { predilection }\end{array}$ & $\begin{array}{c}24(21.7) \\
84(76.5) \\
2(1.7)\end{array}$ & $\begin{array}{c}67(29.8) \\
156(69.3) \\
2(0.89)\end{array}$ & 0.251 \\
\hline
\end{tabular}

NSCLC - non-small cell lung carcinoma 
base change was a $G \rightarrow T$ transversion (12 of 19 mutations). Two of the KRAS mutations were $G \rightarrow C$ transversions and 5 were $G \rightarrow A$ transitions. Still, only three of the patients were ex-smokers (2 ADs with $G \rightarrow$ A mutation and 1 ADSQ with $\mathrm{G} \rightarrow$ T mutation) (Table 4).

\section{Relationship between EGFR and KRAS mutations and clinicopathologic variables}

We assessed the relationship between EGFR and KRAS mutations and the clinicopathologic variables listed in Table 2. No significant association was observed between mutation status and smoking history, tumor size, site, stage and histologic components. There was a statistically significant association between the frequency of EGFR mutations and sex (44.4\% in females versus $11.5 \%$ in males, $p=0.011)$. KRAS mutations were more often found in old age $(26.9 \%$ of cases at age 65 or older, $p=0.02)$. Additionally, all KRAS mutations occurred in non-smokers.

\section{Prognosis and overall survival}

Complete follow-up information was available for 48 cases of PPC. The 5 -year survival rate and median overall survival (OS) time were $40 \%$ and 36.68 months, respectively. Of these patients, 25 (52.08\%) died of disease, with a fol- low-up ranging from 1 to 51 months; 23 patients (47.92\%) were alive, with a follow-up ranging from 23 to 64 months. In univariate analysis, OS was negatively influenced by advanced stage (I-II vs. III-IVA, $p=0.000$ ) and tumor size $(p=0.012)$. None of the other analyzed variables, namely gender, age, lymph node metastasis, smoking history, tumor necrosis, location and EGFR/KRAS mutation, had a significant influence on OS. The multivariate analysis confirmed age $(p=0.019)$, tumor size $(p=0.044)$ and stage $(p=0.000)$ as independent variables for OS (Table 5).

Table 3 shows clinicopathological findings and survival of 21 patients with EGFR and KRAS mutations. The survival data were available for 7 EGFR and 7 KRAS mutated patients. None of the correlations between the 2 groups in OS were statistically significant $(p=0.88)$. More significantly, patient 2 with stage IV disease, a woman who had an exon 19 deletion mutation (E746_A750del), was treated with gefitinib and achieved stable disease. This improvement has lasted for approximately 9 months, and follow-up is underway.

\section{Discussion}

Pulmonary pleomorphic carcinoma of the lung is rare. In the current study, we collected a relatively large number

Table 2. Mutational analysis and clinicopathologic findings of pulmonary pleomorphic carcinomas and comparison of the mutations with those of other NSCLCS

\begin{tabular}{|c|c|c|c|c|c|}
\hline Variable & $N$ & EGFR mutation (\%) & $p$ & KRAS mutation (\%) & $p$ \\
\hline $\begin{array}{l}\text { Age } \\
<65 \\
\geq 65\end{array}$ & $\begin{array}{l}44 \\
26\end{array}$ & $\begin{array}{l}8(18.2) \\
3(11.5)\end{array}$ & 0.461 & $\begin{array}{c}3(6.8) \\
7(26.9)\end{array}$ & 0.02 \\
\hline $\begin{array}{l}\text { Gender } \\
\text { male } \\
\text { female }\end{array}$ & $\begin{array}{c}61 \\
9\end{array}$ & $\begin{array}{l}7(11.5) \\
4(44.4)\end{array}$ & 0.011 & $\begin{array}{c}10(16.4) \\
0(0.0)\end{array}$ & 0.19 \\
\hline $\begin{array}{l}\text { Tumor location } \\
\text { central } \\
\text { predilection } \\
\text { central and predilection }\end{array}$ & $\begin{array}{c}17 \\
52 \\
1\end{array}$ & $\begin{array}{l}4(23.5) \\
7(13.5) \\
0(0.0)\end{array}$ & 0.557 & $\begin{array}{l}4(23.5) \\
6(11.5) \\
0(0.0)\end{array}$ & 0.433 \\
\hline $\begin{array}{l}\text { Tumor size }(\mathrm{cm}) \\
<3 \\
\geq 3\end{array}$ & $\begin{array}{l}14 \\
56\end{array}$ & $\begin{array}{c}1(7.14) \\
10(17.8)\end{array}$ & 0.324 & $\begin{array}{l}2(14.3) \\
8(14.3)\end{array}$ & 1.00 \\
\hline $\begin{array}{l}\text { Smoking status } \\
\text { never } \\
\text { ever }\end{array}$ & $\begin{array}{l}55 \\
15\end{array}$ & $\begin{array}{l}9(16.4) \\
2(13.3)\end{array}$ & 0.775 & $\begin{array}{c}10(18.2) \\
0(0.0)\end{array}$ & 0.074 \\
\hline $\begin{array}{l}\text { Stage } \\
\text { I } \\
\text { II } \\
\text { III } \\
\text { IV }\end{array}$ & $\begin{array}{l}29 \\
14 \\
17 \\
10\end{array}$ & $\begin{array}{l}4(13.8) \\
2(14.3) \\
2(11.8) \\
3(30)\end{array}$ & 0.606 & $\begin{array}{l}6(20.7) \\
3(21.4) \\
0(0.0) \\
1(10)\end{array}$ & 0.209 \\
\hline $\begin{array}{l}\text { Histologic component } \\
\text { AD } \\
\text { SQ } \\
\text { ADSQ } \\
\text { LCC } \\
\text { mixed }\end{array}$ & $\begin{array}{c}36 \\
7 \\
8 \\
1 \\
18\end{array}$ & $\begin{array}{c}10(27.8) \\
1(14.3) \\
2(25) \\
0(0.00) \\
1(5.56)\end{array}$ & 0.645 & $\begin{array}{l}6(16.7) \\
1(14.3) \\
1(12.5) \\
0(0.00) \\
2(11.1)\end{array}$ & 0.973 \\
\hline $\begin{array}{l}\text { Other NSCLC Vs. PPC } \\
\text { AD } \\
\text { SQ } \\
\text { ADSQ } \\
\text { LCC }\end{array}$ & $\begin{array}{l}113 \\
40 \\
55 \\
17\end{array}$ & $\begin{aligned} 48 & (42.5) \\
1 & (2.5) \\
21 & (38.2) \\
0 & (0.0)\end{aligned}$ & $\begin{array}{l}0.000 \\
0.053 \\
0.007 \\
0.112\end{array}$ & $\begin{array}{l}5(4.42) \\
2(5.0) \\
2(3.6) \\
0(0.0)\end{array}$ & $\begin{array}{l}0.025 \\
0.205 \\
0.065 \\
0.199\end{array}$ \\
\hline
\end{tabular}


Table 3. Histologic features and survival of 21 pulmonary pleomorphic carcinomas with EGFR and KRAS mutations

\begin{tabular}{|c|c|c|c|c|c|c|c|c|c|}
\hline Patient & Age/Sex & Size & $\begin{array}{l}\text { Epithelial } \\
\text { component }\end{array}$ & $\begin{array}{l}\text { Sarcoma } \\
\text { component }\end{array}$ & EGFR mutation & $\begin{array}{c}\text { KRAS } \\
\text { mutation }\end{array}$ & $\begin{array}{c}\text { OS } \\
\text { (months) }\end{array}$ & Outcome & Stage \\
\hline 1 & $59 / F$ & 1.8 & $A D$ & spindle & E746-A750del & & 12 & live & T2NOMOIB \\
\hline 2 & $60 / F$ & 3 & $A D$ & mixed & E746-A750del & & 12 & live & T2N2M1IV \\
\hline 3 & $51 / M$ & 4 & $A D$ & spindle & L858R & & 15 & live & T2NOM1IV \\
\hline 4 & $58 / M$ & 3.5 & $A D$ & mixed & L858R & & 3 & dead & T2N2MOIIIA \\
\hline 5 & $55 / M$ & 5 & ADSQ & spindle & L858R & & NA & NA & T2N1MOIIB \\
\hline 6 & $65 / F$ & 5 & $A D$ & mixed & L858R & & NA & NA & T3NOMOIIB \\
\hline 7 & $64 / M$ & 4 & $A D$ & giant & L858R & & 7 & dead & T4N1M1IV \\
\hline 8 & $63 / M$ & 5 & ADSQ & giant & L858R & & 16 & live & T2NOMOIB \\
\hline 9 & $77 / F$ & 4 & ADSQ & mixed & L858R & & No & no & T2N2MOIIIA \\
\hline 10 & $78 / M$ & 4.5 & SQ & mixed & L858R & & 15 & live & T2NOMOIB \\
\hline 11 & $53 / M$ & 5.5 & & mixed & L858R & & NA & NA & T2NOMOIB \\
\hline 12 & $55 / M$ & 11 & $A D$ & mixed & & G12A & NA & NA & T2N1MOIIB \\
\hline 13 & $64 / M$ & 8 & $A D$ & mixed & & $\mathrm{G} 12 \mathrm{C}$ & 34 & live & T2NOMOIB \\
\hline 14 & $56 / M$ & 5.5 & $A D$ & mixed & & $\mathrm{G} 12 \mathrm{C}$ & 7 & dead & T3NOMOIIB \\
\hline 15 & $66 / M$ & 3 & SQ & mixed & & $\mathrm{G} 12 \mathrm{C}$ & NA & NA & T2NOMOIB \\
\hline 16 & $75 / M$ & 7 & $A D$ & mixed & & $\mathrm{G} 12 \mathrm{C}$ & 6 & live & T2N2M1IV \\
\hline 17 & $70 / M$ & 4 & & mixed & & $\mathrm{G} 12 \mathrm{C}$ & 14 & live & T2NOMOIB \\
\hline 18 & $71 / M$ & 2.5 & $A D$ & giant & & G12D & 24 & live & T2NOMOIB \\
\hline 19 & $68 / M$ & 6.5 & ADSQ & giant & & G12D & NA & NA & T3NOMOIIB \\
\hline 20 & $66 / M$ & 7.5 & & mixed & & G12V & 10 & dead & T2N1MOIIB \\
\hline 21 & $75 / M$ & 1 & $A D$ & spindle & & G13C & 10 & dead & T1NOMOIA \\
\hline
\end{tabular}

NA - not available

of PPCs to better define their clinicopathologic features and explored the relationship between EGFR and KRAS mutation status and multiple variables. In agreement with a previous work on PPCs [2], it accounted for $1.57 \%$ (115/6990) of surgically resected NSCLC cases in our department, prevailing in males as a large peripheral lesion. The smokers in our series comprised $37.4 \%(43 / 115)$ and the incidence rate is lower than in other reports [2, 3]. Recently, Mochizuki et al. mentioned that PPC has distinctive clinicopathological features compared with other NSCLCS [17]. Consistent with their report, our analysis demonstrates a higher number of male smokers, older age and larger tumor size.

Since EGFR and KRAS genes were the most clinically relevant molecular biomarkers in NSCLC, we examined the two key oncogenes' characteristics in 70 resected PPCs. Activating EGFR mutations were seen in 11 patients (15.7\%), whereas KRAS mutations were identified in $10 \mathrm{pa}$ tients (14.3\%). Our results revealed that the EGFR mutation rate of $P P C$ is lower than that of $A D$ and $A D S Q$, but might be higher than that of SQ. The KRAS positive rates are largely concordant with the recently evaluated value of 9-22\% in PPC patients [13-15]. Some investigators have also noted that patients with single classical mutations (del-19 or L858R) show a better response to gefitinib than those without the classical mutations [18, 19]. In our study, we identified 10 classical mutations; among these, 2 cases had exon 19 deletions and 8 had L858R point mutations. These results suggested that mutational analysis in patients with PPC should be considered before deciding on a course of treatment. In addition, although there is a male preponderance in PPC, EGFR mutations were also more frequent in females $(p=0.011)$. Consequently, women should be high-priority candidates for EGFR mutation screening. Additionally, in our cohort, 2 tumors with a non-AD component had activating EGFR mutations. Thus, the distribution of EGFR mutation was not associated with the type of malignant epithelial components. Also, KRAS mutations occurred in different subtypes of PPC. Still, we found that KRAS mutation was more frequently detected in older patients than younger patients (age $\geq 65$ vs. $<65)$ ( $p=0.02$ ).

With regard to the histogenesis of PPC, two possible pathways have been proposed, divided into monoclonal and polyclonal pathways. Kyoichi Kaira et al. described 
Table 4. Relationship between KRAS mutation type and smoking history in NSCLCS

\begin{tabular}{|c|c|c|}
\hline NSCLCs & KRAS mutation type & Smoking history \\
\hline$P P C$ & G12A $(\mathrm{GGT} \rightarrow \mathrm{GCT})$ & no \\
\hline PPC & G12C (GGT $\rightarrow$ TGT) & no \\
\hline PPC & G12C (GGT $\rightarrow$ TGT) & no \\
\hline PPC & G12C (GGT $\rightarrow$ TGT) & no \\
\hline$P P C$ & G12C (GGT $\rightarrow$ TGT) & no \\
\hline$P P C$ & G12C (GGT $\rightarrow$ TGT) & no \\
\hline PPC & G12D (GGT $\rightarrow$ GAT) & no \\
\hline PPC & G12D (GGT $\rightarrow$ GAT) & no \\
\hline$P P C$ & G12V (GGT $\rightarrow$ GTT) & no \\
\hline PPC & G13C (GGT $\rightarrow$ TGT $)$ & no \\
\hline$A D$ & $\mathrm{G} 12 \mathrm{C}(\mathrm{GGT} \rightarrow \mathrm{TGT})$ & no \\
\hline$A D$ & G12D (GGT $\rightarrow$ GAT) & yes \\
\hline$A D$ & G12D (GGT $\rightarrow$ GAT) & yes \\
\hline$A D$ & G12V (GGT $\rightarrow$ GTT) & no \\
\hline$A D$ & G12V (GGT $\rightarrow \mathrm{GTT})$ & no \\
\hline SQ & G12R (GGT $\rightarrow$ CGT) & no \\
\hline SQ & G12S (GGT $\rightarrow$ AGT) & no \\
\hline ADSQ & G12C (GGT $\rightarrow$ TGT $)$ & yes \\
\hline ADSQ & G12C (GGT $\rightarrow$ TGT) & no \\
\hline
\end{tabular}

$P P C$ - pulmonary pleomorphic carcinoma: $A D$ - adenocarcinoma; $S O$ - squamous cell carcinoma: ADSO - adenosquamous carcinoma

three patients with two different histologic types exhibiting EGFR mutations. Their cases revealed that the adenocarcinomatous component had an EGFR mutation and the sarcomatoid component did not [20]. In our series, in contrast, we found that both epithelial and sarcomatoid components carried identical EGFR and KRAS mutations, favoring the contention that PPCS were monoclonal in origin $[16,21]$.
Another interesting finding is the lack of association between KRAS mutation and smoking. In our studies, even though it was not statistically significant ( $p=0.074)$, non-smokers tended to exhibit KRAS mutations more commonly $(10 / 55,18.2 \%)$ than smokers (0/15, $0.0 \%)$. In addition, in comparison with other NSCLCS, smokers were more frequent in the PPC group $(p=0.039)$. Consequently, we speculated that although smoking is a risk factor for the development of PPC, it may be less strongly associated with KRAS mutations in Chinese patients, arguing against the notion that a11 KRAS mutations are confined to smokers [15].

Ahrendt et al. reported that in KRAS transversions (substituting a pyrimidine for a purine, or a purine for a pyrimidine) are more common than transitions (substituting a purine for a purine, or a pyrimidine for a pyrimidine), and KRAS mutations were significantly more frequent in lung ADs from smokers compared with those from nonsmokers (43\% vs. $0 \% ; p=0.001$ ) [22]. Riely et al. found that KRAS transversion mutations $(\mathrm{G} \rightarrow T$ or $\mathrm{G} \rightarrow \mathrm{C}$ ) were more common in smokers with lung AD [23]. In contrast, our studies demonstrated that KRAS mutations in $A D$ were present in only 5 (4.42\%) patients. Of the 5 mutations, 2 in smokers were transition mutations and 3 in non-smokers were transversion mutations. Also, we found that most never smokers have transversion mutations $(G \rightarrow T)$ in PPCs and other NSCLCs. The discrepancy might be attributed to geographical or racial differences in these studies. However, the distinct profile of KRAS mutations observed here in never smokers further suggests that while some mutations in KRAS are associated with cigarette smoking, KRAS tumor status cannot be easily predicted on the basis of smoking history alone.

Several researchers [24-26] have reported that gefitinib was effective in PPC patients with L858R EGFR mutation. In our series, one patient who had a deletion mutation in exon 19 of EGFR and was treated with gefitinib achieved SD. These findings may suggest that gefitinib is effective in PPC with EGFR mutation. Our study also indicated that sex, smoking history, lymph node status, mutation type, tumor size and site did not have an impact on length of survival, whereas old age and late stage may have significant value in predicting a poor prognosis.

In summary, we observed a similar EGFR and KRAS mutation rate in Chinese PC patients. Our findings fur-

Table 5. Univariate and multivariate analyses concerning PPC $(n=48)$

\begin{tabular}{|c|c|c|c|c|}
\hline \multirow[t]{2}{*}{ Variables } & \multirow[t]{2}{*}{ Univariate $p$ value } & \multicolumn{3}{|c|}{ Multivariate } \\
\hline & & $p$ value & HR & $95 \% \mathrm{Cl}$ \\
\hline male vs. female & 0.992 & 0.964 & 0.961 & $0.169-5.453$ \\
\hline age $(y) \geq 65$ vs. $<65$ & 0.081 & 0.019 & 0.297 & $0.108-0.816$ \\
\hline tumor size $\geq 3 \mathrm{~cm}$ vs. $<3 \mathrm{~cm}$ & 0.012 & 0.004 & 0.255 & $0.068-0.962$ \\
\hline with vs. without tumor necrosis & 0.053 & 0.239 & 0.549 & $0.202-1.489$ \\
\hline early stage vs. late stage & 0.000 & 0.000 & 0.061 & $0.020-0.183$ \\
\hline with vs. without EGFR/KRAS mutation & 0.709 & 0.649 & 0.857 & $0.443-1.661$ \\
\hline smoking vs. no smoking & 0.516 & 0.919 & 1.066 & $0.310-3.672$ \\
\hline
\end{tabular}

$H R$ - hazard ratio; Cl-confidence interval 
ther confirmed that some patients with PPC may possess active EGFR mutations and benefit from EGFR-targeted therapies. Of note, EGFR mutations in PPC were commonly identified in women; therefore women should be high-priority candidates for EGFR mutation screening.

The authors declare no conflict of interest.

This work was supported by the Fundamental Research Funds for the Central Universities (grant No. 1511219018) and by the grant from Youth Research Project of Shanghai Municipal Health Bureau (grant No. 20124y088).

\section{References}

1. Chang YL, Lee YC, Shih JY, Wu CT. Pulmonary pleomorphic (spindle) cell carcinoma: peculiar clinicopathologic manifestations different from ordinary non-small cell carcinoma. Lung Cancer 2001; 34: 91-7.

2. Yuki T, Sakuma T, Ohbayashi C, Yoshimura M, Tsubota N, Okita Y, Okada M. Pleomorphic carcinoma of the lung: a surgical outcome. J Thorac Cardiovasc Surg 2007; 134: 399-404.

3. Ito K, Oizumi S, Fukumoto S, et al. Clinical characteristics of pleomorphic carcinoma of the lung. Lung Cancer 2010; 68: 204-210.

4. Travis D, Brambilla E, Müller-Hermelink HK, Harris CC. WHO classification. Tumors of the lung, pleura, thymus and heart. Albany, NY: WHO Publication Center, 2004.

5. Fishback NF, Travis WD, Moran CA, Guinee DG Jr, McCarthy WF, Koss MN. Pleomorphic (spindle/giant cell) carcinoma of the lung. A clinicopathologic correlation of 78 cases. Cancer 1994; 73: 2936-45.

6. Rossi G, Cavazza A, Sturm N, Migaldi M, Facciolongo N, Longo L, Maiorana A, Brambilla E. Pulmonary carcinomas with pleomorphic, sarcomatoid, or sarcomatous elements: a clinicopathologic and immunohistochemical study of 75 cases. Am J Surg Pathol 2003; 27: 311-24.

7. Mitsudomi T, Kosaka T, Endoh H, et al. Mutations of the epidermal growth factor receptor gene predict prolonged survival after gefitinib treatment in patients with non-small-cell lung cancer with postoperative recurrence. J Clin Oncol 2005; 23: 2513-20.

8. Taron $M$, Ichinose $\mathrm{Y}$, Rosell $\mathrm{R}$, et al. Activating mutations in the tyrosine kinase domain of the epidermal growth factor receptor are associated with improved survival in gefitinib-treated chemorefractory lung adenocarcinomas. Clin Cancer Res 2005; 11: 5878-85.

9. Shigematsu H, Lin L, Takahashi T, et al. Clinical and biological features associated with epidermal growth factor receptor gene mutations in lung cancers. J Natl Cancer Inst 2005; 97: 339-46.

10. Fukui T, Mitsudomi T. Mutations in the epidermal growth factor receptor gene and effects of EGFR-tyrosine kinase inhibitors on lung cancers. Gen Thorac Cardiovasc Surg 2008; 56: 97-103.

11. Italiano A, Cortot AB, Ilie M, et al. EGFR and KRAS status of primary sarcomatoid carcinomas of the lung: Implications for an ti-EGFR treatment of a rare lung malignancy. Int J Cancer 2009; 125: 2479-82.

12. Pelosi G, Gasparini P, Cavazza A, et al. Multiparametric molecular characterization of pulmonary sarcomatoid carcinoma reveals a nonrandom amplification of anaplastic lymphoma kinasem (ALK) gene. Lung Cancer 2012; 77: 507-51.

13. Leone A, Graziano P, Gasbarra R, et al. Identification of EGFR mutations in lung sarcomatoid carcinoma. Int J Cancer 2011; 128: 732-5.

14. Lee S, Kim Y, Sun JM, et al. Molecular profiles of EGFR, K-ras, c-met, and FGFR in pulmonary pleomorphic carcinoma, a rare lung malignancy. J Cancer Res Clin Oncol 2011; 137: 1203-11.

15. Pelosi G, Scarpa A, Manzotti M, et al. K-ras gene mutational analysis supports a monoclonal origin of biphasic pleomorphic carcinoma of the lung. Mod Pathol 2004; 17: 538-46.

16. Jia XL, Chen G. EGFR and KRAS mutations in Chinese patients with adenosquamous carcinoma of the lung. Lung Cancer 2011; 74: 396-400.
17. Mochizuki T, Ishii G, Nagai K, et al. Pleomorphic carcinoma of the lung: clinicopathologic characteristics of 70 cases. Am J Surg Pathol 2008; 32: 1727-35.

18. Riely GJ, Pao W, Pham D, et al. Clinical course of patients with non-small cell lung cancer and epidermal growth factor receptor exon 19 and exon 21 mutations treated with gefitinib or erlotinib. Clin Cancer Res 2006; 12: 839-44.

19. Takano T, Ohe Y, Sakamoto H, et al. Epidermal growth factor receptor gene mutations and increased copy numbers predict gefitinib sensitivity in patients with recurrent non-small-cell lung cancer. J Clin Oncol 2005; 23: 6829-37.

20. Kaira K, Horie Y, Ayabe E, et al. Pulmonary pleomorphic carcinoma: a clinicopathological study including EGFR mutation analysis. J Thorac Oncol 2010; 5: 460-5.

21. Chang YL, Wu CT, Shih JY, Lee YC. EGFR and p53 status of pulmonary pleomorphic carcinoma: implications for EGFR tyrosine kinase inhibitors therapy of an aggressive lung malignancy. Ann Surg Oncol 2011; 18: 2952-60.

22. Ahrendt SA, Decker PA, Alawi EA, et al. Cigarette smoking is strongly associated with mutation of the K-ras gene in patients with primary adenocarcinoma of the lung. Cancer 2001; 92: 1525-30.

23. Riely GJ, Kris MG, Rosenbaum D, et al. Frequency and distinctive spectrum of KRAS mutations in never smokers with lung adenocarcinoma. Clin Cancer Res 2008; 14: 5731-4.

24. Bae HM, Min HS, Lee SH, Kim DW, Chung DH, Lee JS, Kim YW, Heo DS. Palliative chemotherapy for pulmonary pleomorphic carcinoma. Lung Cancer 2007; 58: 112-5.

25. Saitoh M, Niijima M, Takiguchi Y, Hiroshima K, Fujita Y, Nishio K, Tatsumi K. An early event of EGFR mutation in pleomorphic carcinoma of the lung. Int J Clin Oncol 2011; 16: 770-3.

26. Ji-Yeon K, Yoojoo L, Eunyoung L, et al. Gefitinib treatment for pulmonary sarcomatoid carcinoma driven by an EGFR mutation: two cases. Korean J Med 2013; 84: 446-51.

\section{Address for correspondence}

\section{Xiaoli Jia}

Department of Pathology, Shanghai Pulmonary Hospital

Tongji University School of Medicine Shanghai

507 Zhengmin Road

200433 Shanghai, China

e-mail: xlxljia@126.com

Submitted: 17.02.2014

Accepted: 11.04 .2014 